\title{
¿DES-gol-ONIZACIÓN? Fútbol y política en los movimientos indígenas de Bolivia
}

DES-gol-ONIZACIÓN? Football and Politics in Indigenous Movements in Bolivia DÉ-goal-ONISATION? Football et politique dans les mouvements indigènes en Bolivie

\section{Sergio Villena Fiengo}

\section{OpenEdition}

\section{Journals}

\section{Edición electrónica}

URL: http://journals.openedition.org/rccs/6439

DOl: $10.4000 /$ rccs.6439

ISSN: 2182-7435

\section{Editor}

Centro de Estudos Sociais da Universidade de Coimbra

\section{Edición impresa}

Fecha de publicación: 1 diciembre 2016

Paginación: 3-32

ISSN: 0254-1106

\section{Referencia electrónica}

Sergio Villena Fiengo, « ¿DES-gol-ONIZACIÓN? Fútbol y política en los movimientos indígenas de Bolivia », Revista Crítica de Ciências Sociais [En línea], 111 | 2016, Puesto en línea el 07 diciembre 2016, consultado el 20 abril 2019. URL : http://journals.openedition.org/rccs/6439 ; DOI : 10.4000/ rccs. 6439 


\section{SERGIO VILLENA FIENGO}

\section{¿DES-gol-ONIZACIÓN? \\ Fútbol y política en los movimientos indígenas de Bolivia}

Este ensayo presenta una aproximación al "fútbol indígena" boliviano, aportando indicios e hipótesis acerca del lugar que ocupa el deporte en los procesos de colonialidad y descolonización. Basándonos en la teoría del "control cultural" y utilizando fuentes secundarias, estudiamos cómo a lo largo de aproximadamente un siglo, el fútbol ha arraigado como "cultura apropiada" entre las comunidades y los movimientos indígenas aimara y cocalero en Bolivia. Mostraremos cómo, en ese devenir, el "fútbol indígena" ha servido para múltiples propósitos: fortalecer las identidades locales, expresar pertenencia a la nación, organizar sindicatos, formar líderes y redes indígenas, resistir al embate de las dictaduras, oponerse a las políticas neoliberales, promover políticas de integración nacional y apuntalar un proyecto indianista de oposición.

Palabras clave: Bolivia; fútbol; movimientos indígenas; oposición política; política deportiva; sindicalismo.

Palavras-chave: Bolívia; futebol; movimentos indígenas; oposição política; política desportiva; sindicalismo.

Un Aleph es uno de los puntos del espacio que contiene todos los puntos.

J. L. BORGES

El fútbol tiene algo de Aleph. Es el punto nodal de diversas dialécticas: civilización y barbarie, tradición y modernidad, occidentalización e indigenización, nacionalismo y globalización, integración nacional y conflicto secesionista. Entre esas múltiples dialécticas, nos interesa aquí estudiar la colonialidad/resistencia en Bolivia, país donde la población indígena tiene una gran importancia política y demográfica. ${ }^{1}$ Enfocamos nuestra atención

${ }^{1}$ La población indígena en Bolivia ha variado entre el 62,0\% (censo del 2001) y el 40,58 \% (censo del 2012). Los grupos lingüísticos más importantes (2001) son: quechua (30,7\% de la población) y aimara (25,2\%); otros constituyen el 6,1\% (guaraní y otras lenguas). La Constitución del 2009 reconoce 36 nacionalidades indígenas y un grupo "intercultural” (campesinos cocaleros). 
en conocer el papel que ha tenido este deporte en la organización y movilización de los pueblos indígenas, en el mundo aimara y entre los campesinos productores de coca o "interculturales", atendiendo a las siguientes cuestiones: ¿Cómo se ha articulado en ese proceso la difusión del fútbol con las dinámicas del colonialismo interno? ¿Las prácticas y las aficiones deportivas han sido el instrumento de los sectores dominantes criollo-mestizos para mantener y prolongar el colonialismo interno? $\mathrm{O}$, por el contrario, ¿`se puede considerar al fútbol como una herramienta útil para los procesos de resistencia y reivindicación de las identidades y los derechos indígenas?

Siguiendo la teoría del "control cultural” de Guillermo Bonfil Batalla (1987), mostraremos cómo el fútbol -un elemento cultural en principio ajeno-fue apropiado y convertido por los pueblos indígenas en instrumento adecuado para fortalecer sus vínculos internos y generar identidad local, así como un espacio contrahegemónico para apuntalar una política anticolonial de alcance nacional. Más aún, con la conformación de un gobierno nacional indígena -inédito en América Latina-, el fútbol ha trascendido su función "táctica" de resistencia comunitaria y sindical, para convertirse en una herramienta "estratégica" del presidente Evo Morales, sin perder por ello su carácter como instrumento de la oposición indígena a ese mismo gobierno.

La "teoría del control cultural" pone en duda la extinción de las identidades indígenas por el avance del mestizaje al postular que lo importante no son per se los préstamos culturales, sino la capacidad de "control" indígena sobre los "elementos" culturales que adoptan. Esas dos variables (categorizadas en propio/ajeno), conforman una matriz analítica con cuatro posibilidades: elementos propios y control ajeno (cultura enajenada), elementos ajenos y control ajeno (cultura impuesta), elementos propios y control propio (cultura propia) y elementos ajenos y control propio (cultura apropiada). Desde esta teoría, que guarda afinidades con la de De Certeau (1996) sobre la producción cultural popular, con la teoría de Gramsci sobre la hegemonía/contrahegemonía y con los debates sobre la "decolonialidad", sostenemos que el fútbol es "cultura indígena apropiada", dado que ha sido incorporado a su matriz cultural según sus propios términos y objetivos descolonizadores. ${ }^{2}$ Ese relativo "control" indígena se ha ido ampliando de manera escalonada, desde el ámbito local al regional, alcanzando incluso -con el gobierno de Evo Morales (del 2006 en adelante)- el ámbito nacional.

\footnotetext{
${ }^{2}$ El enfoque colonialidad/decolonialidad, en América Latina, sostiene que la emancipación social requiere un proceso de descolonización que termine de una vez por todas con las persistentes relaciones sociales, políticas y culturales lastradas por la estructura social racializada heredada de la colonia, de las cuales derivan las "colonialidades" del poder, el saber y el ser (ver Santos y Meneses, 2014).
} 
Por lo tanto, postulamos que la "des-gol-onización" ha avanzado desde la consolidación de las identidades indígenas locales hacia la reivindicación de su pertenencia a la nación e, incluso, hacia la fundación de una nueva hegemonía desde el Estado.

Para respaldar estas hipótesis, realizaremos un análisis hermenéutico de fuentes secundarias, como libros de historia del movimiento indígena y biografías de los líderes del mismo, así como de noticias, crónicas y reportajes publicados en periódicos, para la época más reciente. El periodo en estudio abarca aproximadamente un siglo y se divide, provisionalmente, en cinco etapas: a) La recepción del fútbol (1920-1952); b) La Revolución Nacional (1952-1964); c) El movimiento indígena independiente (de los años setenta y ochenta); d) El sindicalismo cocalero (de los años ochenta al 2005), e) El gobierno de Evo Morales (del 2006 en adelante), y f) La incursión indígena en el fútbol profesional (a partir del 2004).

\section{La recepción indígena del fútbol (1920-1952)}

En Bolivia, las historias del fútbol se han enfocado generalmente en los procesos de recepción, institucionalización y profesionalización en los principales centros urbanos (p. ej., Peñaloza, 1993). Afortunadamente, una reciente publicación explora ese "otro fútbol" y aporta a la historia tanto la recepción y apropiación del fútbol entre las poblaciones indígenas de la zona rural andina y entre las poblaciones urbanas populares, como en las comunidades de emigrantes residentes en países del norte, como España y Estados Unidos.

Juliane Müller reconstruye la difusión del fútbol entre las poblaciones aimara en un periodo temprano (1910-1940), destacando el papel de las primeras escuelas rurales en la incorporación de la educación física. La antropóloga resalta "la capacidad de acción de los sujetos subalternos y de los procesos de apropiación y criollización cultural por la interacción de prácticas y significados", de manera que "el deporte no es únicamente una herramienta de poder para disciplinar a los sectores sociales más bajos y étnicamente diferentes y para reproducir una fuerza de trabajo físicamente sana" (Müller, 2014: 31). Según la autora, el fútbol fue utilizado por los comunarios "como un pretexto para reunirse y camuflar el objetivo político de las agrupaciones", como clubes y equipos, de tal manera que "aparece como un campo donde se viven y expresan formas diarias de resistencia y conflictos de las cuales nos hablan los teóricos de la subalternidad." (ibidem).

El fútbol, articulado con los festejos y las expresiones folclóricas en el altiplano, serviría como arena de competición entre comunidades enfrentadas, más que para el conflicto interétnico entre indígenas y mestizos/criollos, quienes practicaban los deportes de manera segregada. Müller analiza 
un conflicto entre Warisata y Achacachi, bastiones de la lucha indígena en el siglo Xx, llegando a la siguiente conclusión: "el fútbol llegó a crear tempranamente en Bolivia un foro para la puesta en escena de los conflictos sociales y políticos, por cuanto el futbol de base rural funcionaba como un campo local de encuentro entre personas y grupos sociales y étnicos, diferentemente posicionados en un contexto donde una victoria llegaba a invertir momentáneamente una relación de poder." (ibidem: 64).

En la Guerra del Chaco (1932-1936) se forma "la conciencia nacional" boliviana. Según René Zavaleta Mercado, en las calientes arenas donde se combate contra Paraguay surge el sentido de nacionalidad entre los indígenas, pues su reclutamiento forzado y masivo afianzó su sentimiento de pertenencia y creó las condiciones para la demanda de derechos ciudadanos. La derrota precipitó la debacle de la oligarquía liberal-republicana, estimulando un proyecto nacional con amplia participación popular que fue emergiendo y alcanzó su cúspide con la Revolución de 1952-1964, protagonizada por las nuevas generaciones militares, los intelectuales de clase media, las masas campesinas y los movimientos mineros de la región andina, donde se concentraba el principal sustento de la economía nacional.

Queda por investigar la práctica deportiva durante el conflicto bélico y en las movilizaciones políticas posteriores en los agitados años de la posguerra, cuando los gobiernos militares de Toro, Busch y Villarroel llevaron adelante importantes reformas, entre ellas la nacionalización del petróleo, el reconocimiento de los sindicatos, el establecimiento de derechos laborales, la abolición de la servidumbre indígena (pongueaje y mitaje) y el impulso a la organización y movilización indígena, cuyo momento fundacional fue el Primer Congreso Nacional Indígena (1945).3 Según Müller, el "socialismo militar" incorporó el fútbol en las celebraciones cívicas en las comunidades aimara, entre las que destacaba el "Día del Indio" (2 de agosto), establecido en 1939.

\section{Revolución y "sindicalización del fútbol" (1952-1964)}

Pablo Quisbert, en "Tiempos de Revolución, Tiempos de fútbol. Nacionalismo, identidad obrera y fútbol en la Revolución Nacional de 1952” (2014), señala que con la revolución se produce una expansión del fútbol y su constitución como deporte popular en las regiones rurales del país, especialmente

\footnotetext{
${ }^{3}$ Calderón y Dandler resumen así los avances y retrocesos en la "cuestión indígena" durante estos años: "En torno al problema agrario, el discurso político se centró en la educación del 'indígena' durante los años treinta; en los años cuarenta se enfocó en el problema de la servidumbre y fue a raíz de la Revolución de 1952 y a través de la movilización campesina, que recién se cristalizó directamente una acción sobre la tierra y su redistribución.” (1986: 204).
} 
en el altiplano andino. Esa práctica se habría beneficiado tanto de la mayor disponibilidad de tiempo libre por parte los campesinos, liberados del régimen de hacienda y la servidumbre semifeudal, como de las reformas educativas, pues la creación de "innumerables" escuelas rurales habría introducido la educación física, fomentando así los deportes, entre los cuales el fútbol "tenía además la ventaja de ser un pasatiempo sencillo y barato".

Según ese autor, los campesinos asumieron el fútbol como un "símbolo de los nuevos tiempos", útil para afirmar ya no sólo la identidad local, sino también la pertenencia nacional, acorde con los postulados integradores de la revolución. Su difusión se habría nutrido de las medidas orientadas a la ampliación de la ciudadanía de la población indígena y la promoción del mestizaje mediante elementos culturales occidentales, como el idioma castellano y nuevas formas de sociabilidad y participación política y económica. La reforma agraria, la sindicalización campesina, la reforma educativa, el sufragio universal y la reforma del ejército, habrían contribuido para hacer del fútbol un componente imprescindible de los programas educativos, las festividades locales y las celebraciones cívicas.

El balompié se habría institucionalizado sobre todo gracias a la creación de "sindicatos campesinos y de la inclusión en sus directivas de secretarías de deporte, que se dedicaban, casi en exclusiva a la organización de campeonatos de fútbol" (Quisbert, 2014: 76). Como resultado, "el paisaje del campo se fue transformando con la aparición de canchas de fútbol, como lo muestra una secuencia de Las montañas no cambian, documental de 1962 destinado a ensalzar los logros de la Revolución Nacional." (ibidem: 75).

Según Esteban Ticona, entre los años veinte y el periodo revolucionario, la apropiación del fútbol se fue produciendo en los siguientes términos:

El fútbol se empezó a jugar en las áreas rurales ya por los años veinte. Al principio se jugaba con una t'ijita (pelota de trapo), entre numerosos equipos. Después de la Reforma Agraria de 1953, los indígenas y campesinos adoptaron todas las reglas de juego del deporte inglés y el fútbol se constituyó en una de las manifestaciones más populares del "mundo aymara", incluido el sector femenino. (2000:53)

Dado su creciente arraigo en el universo indígena, no extraña que -como señala Müller- el fútbol fuera un componente habitual en las celebraciones del 2 de agosto, que desde 1953 se denominó "Día del Campesino", en sustitución al "Día del Indio".

El sindicalismo campesino se impuso con la Revolución de 1952, iniciando una tensión constante con la organización comunitaria, pues esa nueva organización cumplía funciones que desbordaban su carácter 
corporativo, situándose en el núcleo de la vida local y articulando el vínculo con el gobierno. También aportó un espacio institucionalizado para la promoción del fútbol mediante una secretaría de deportes permanente, contribuyendo a su arraigo entre la población adulta, mientras que entre la población infantil se había difundido sobre todo en el ámbito escolar. En el futuro, esa articulación orgánica entre fútbol y sindicalismo tendría importantes consecuencias para ambas actividades, como veremos.

Los deportes también fueron incorporados en las escuelas normales rurales, donde se formaban los maestros para las zonas indígenas, así como en las reformadas fuerzas armadas a partir de 1956, cuando se reconfigura el servicio militar obligatorio, establecido desde 1907, para incluir a la población indígena. Según Quintana (1998), el ejército dejó de ser una fuerza al servicio de la oligarquía, para transformarse en un ejército nacional con el fin, entre otros, de impartir formación cívica e incorporar a la población indígena al Estado nacional. El servicio militar sustituyó a las milicias establecidas durante la Revolución, convirtiendo al campesinado en la base social de la dictadura de Barrientos, quien estableció el pacto militar-campesino y fue un verdadero caudillo entre los campesinos quechua, de donde era oriundo.

El sentimiento de nacionalidad entre los sectores populares urbanos y rurales, se afianzó también gracias al éxito deportivo logrado en el Campeonato Sudamericano de 1963 (XXVIII Copa América). Organizado para exhibir ante América Latina los avances del país durante los años revolucionarios, este torneo fue un escenario apoteósico para el título de campeón invicto logrado por la "verde". Muy significativo fue el triunfo ( 2 a 0 ) contra Paraguay, país con el cual Bolivia había protagonizado un conflicto bélico unas décadas atrás. Zavaleta Mercado decía que Bolivia perdió la guerra, pero ganó una revolución... se podría añadir que, para algunos, esa revolución hizo posible el triunfo deportivo como revancha histórica. En cualquier caso, en pleno auge del nacionalismo, la "gloria del 63” contribuyó a configurar un tejido intersubjetivo nacional que sobrevivió incluso a la revolución.

\section{El fútbol y el movimiento indígena independiente (años setenta)}

Concluida la revolución en 1964, el fútbol asumió nuevas funciones: facilitó la formación de líderes comunitarios, el surgimiento del movimiento aimara katarista y la organización de la resistencia indígena a la dictadura de Banzer (1971-1978). Por entonces emerge una nueva generación de dirigentes entre las filas del sindicalismo campesino, apalancados frecuentemente por la práctica deportiva: 
El fútbol se convierte en una especie de empuje de ascenso de los jóvenes que se enfrentan con los mayores en las decisiones del ayllu: el fútbol es un catalizador, puesto que es una actividad nueva, que se masifica con los cambios estructurales de la Revolución del 52 y es apropiado por las nuevas generaciones. (Ticona, 2000: 77)

Los sindicatos campesinos, perseguidos por la dictadura de Bánzer, utilizarían el fútbol como una esfera pública plebeya que, por un lado, rezuma "modernidad" estableciendo cierta pauta de movilidad social y política de carácter meritocrático, pero también afianza una nueva "economía moral" indígena. Según Ticona:

La organización de campeonatos de fútbol dentro del ayllu, crea otras expectativas y el "juego deportivo" cada vez más, adquiere un significado simbólico importante, hasta el punto de contraponerse a las actividades "tradicionales" y entre los jóvenes establece una nueva imagen "moderna" del comunario. De alguna manera, la masificación del fútbol corresponde a la extensión de la ciudadanía y esto ilustra el espacio donde sobresale el individuo en un conjunto y el grupo (como equipo de fútbol) por su propia habilidad y consenso, sin depender de las relaciones fuera del campo de juego, ni las vinculaciones familiares, ni el prestigio de los antepasados. Se valora la destreza, la rapidez, la capacidad de esquivar o "burlar" al adversario y por último, la competencia y el triunfo. (ibidem: 77)

Así, el fútbol se convierte en un lugar de concurrencia social donde los jóvenes aimara compiten públicamente entre sí por prestigio y poder, desplazando a los líderes comunitarios mayores y consolidando una renovación de la conducción sindical. Sin dejar de ser un espacio de adhesión a los nuevos valores "modernos" del mestizaje y la occidentalización, el deporte opera como escenario para la adquisición de prestigio y acumulación de capital social y político, dentro y fuera de la comunidad. Según el mismo autor:

[...] es particularmente significativo que para expresar sus reivindicaciones los jóvenes decidan elegir un secretario general del "sindicato" (como fue el caso de Jenaro Flores), que no solamente corresponde a la trayectoria de ruptura de la nueva generación, sino que forma parte de ella: era probablemente lo que muchos jóvenes soñaban lograr: salir del ayllu, ir a las ciudades, estudiar en un colegio, ser buen futbolista, y "retornar" a la comunidad cargado de prestigio ganado afuera, para ocupar un puesto alto e impulsar cambios. (ibidem: 77)

Pero esos líderes, que emergieron en parte gracias a sus habilidades deportivas u organizativas en el ámbito del fútbol, verán frustradas las 
promesas de integración hechas por la Revolución del 52 y se convertirán en críticos radicales de la "solución" del mestizaje. Ellos se constituirán en un referente de las luchas indígenas dentro del sindicalismo aimara independiente y tendrán que enfrentar la arremetida criolla/mestiza de la dictadura de Banzer. Uno de esos nuevos líderes es Jenaro Flores, quien en 2012 narraría a Müller su elección -con 17 años- como primera autoridad en su comunidad:

[En] un campeonato relámpago a otra sección, a otra [sic] cantón donde han participado 40 equipos de puro niño campesino, ahí hemos salido campeones nosotros. La gente 'ese Llokalla [chico] come chuño [papa deshidratada]' me decían porque yo he metido el gol del triunfo [...] Hemos sido campeón, con trofeo hemos llegado, con fiesta en la comunidad me han festejado. Después de eso la gente ha dicho que nos den pelota, uniforme [...] A la comunidad le hemos planteado que nos den para jugar, [pero] la gente ha rechazado, 'no hay plata' [han dicho]. Entonces la gente joven 'entonces nosotros nos hacemos cargo de la Jilacatura' [la jefatura de la comunidad]. Es como sindicato [...], de ahí yo he postulado para ser Jilacata de la comunidad, toda la gente me ha apoyado, me nombraron Jilacata, primera autoridad de la comunidad [...]. Jovencito, 17 años y yo soy Jilacata ya, he dirigido la jefatura, ahí empieza mi carrera sindical. Mi carrera política ese día empieza. Toda la gente contento [sic], feliz, [porque] yo he conseguido pelotas [,] uniformes, banderas, todo para la gente joven porque la gente joven no tiene plata, yo he conseguido pues. (Müller y Murillo, 2014: 13)

Pero el fútbol contribuyó no sólo para renovar los liderazgos, sino también en la formación de una nueva confederación sindical campesina supralocal. La organización de campeonatos en el altiplano aimara, no censurados por la dictadura que consideraba que el deporte ayudaba a combatir el "vicio" de la política ("mente sana en cuerpo sano"), facilitaría la formación clandestina de una poderosa organización que protagonizó la resistencia contra los golpes militares de Natush Busch (1979) y García Mesa (1980). Jenaro Flores sería el primer Secretario General de dicha organización, la Confederación Sindical Única de Trabajadores Campesinos de Bolivia (CSUTCB), creada a fines de la década de los setenta y actor colectivo de primera línea en la vida política nacional en las décadas siguientes.

Las actividades deportivas participaron también en la articulación de redes de movilidad espacial e intercambio entre el campo y la ciudad. Según Albó y colaboradores, entre los múltiples canales institucionales que permitían "cabalgar entre dos mundos" (Albó et al., 1983), destacan las asociaciones 
de residentes campesinos que integraban en la vida urbana a los nuevos inmigrantes, a la vez que difundían la "modernidad" en sus comunidades de origen. El testimonio de un "vecino" evidencia la importancia del deporte en el mantenimiento de vínculos con la comunidad, así como en el imaginario del progreso que se proyecta sobre las mismas:

El Centro de residentes [lo] organizamos en 1952. Los pueblos necesitan muchos adelantos: escuelas, agua potable, [re]modelación de la plaza, campos deportivos, etc. Entonces, fundamos el centro con la finalidad de hacer adelantar el pueblo. (Albó et al., 1987: 101)

Juliana Ströbele-Gregor, al estudiar la difusión del protestantismo entre los aimaras, confirmó el papel central de las asociaciones deportivas en la configuración de ese mundo dual. La importancia social y política del fútbol en las zonas indígenas de las ciudades siamesas de El Alto y La Paz, se pone de manifiesto en el siguiente pasaje que muestra además una relativa separación funcional entre las organizaciones deportivas "clubes" agrupados en "ligas" - y otras formas de organización social como los sindicatos, las asociaciones de residentes, las juntas vecinales y las fraternidades folclóricas:

Los clubes de fútbol se cuentan, tanto en el campo como en la ciudad, entre las organizaciones más importantes. A la hora de establecer relaciones mutuas entre los residentes o entre ellos y los demás habitantes de la ciudad, gozan de la mayor popularidad y en la encuesta figuraban en primer lugar. En 1975 Sandoval contaba 130 ligas de fútbol. Su membresía es heterogénea, tanto desde el punto de vista social como de edad. Sobre la base del deporte no sólo se establecen contactos sociales sino también políticos. En tiempos de dictadura y de la democracia restringida esta posibilidad poco sospechosa de reunión jugó un papel nada despreciable. (Ströbele-Gregor, 1989: 81)

Esa socióloga relata los métodos de preparación de los procesos migratorios entre el campo y la ciudad, entre los que destacan también las actividades folclóricas, organizadas en "fraternidades", fundamentales en la vida social de estas poblaciones:

La preparación para la migración puede concebirse como una premeditada extensión de la red local de relaciones sociales. La red tradicional de parientes, compadres, amigos del club de fútbol, del grupo musical o de otros organismos comunales, se dilata hacia la ciudad, si bien todavía no existen relaciones estables con ella, 
a través de la adquisición de nuevas relaciones de compadrazgo o nuevos lazos en el plano de grupos festivos. (ibidem: 67-68)

No es extraño pues que, gracias a sus habilidades deportivas, Flores pudiese moverse con fluidez en ese mundo dual e incluso ganara un lugar en una ciudad hostil al migrante indígena, donde logró incorporarse en "la segunda división del club Municipal, equipo profesional de la Alcaldía de La Paz y de mucha popularidad en la población paceña" (Ticona, 2000: 53).

En suma, el fútbol se había transformado en una extensa esfera pública indígena, favoreciendo el desarrollo de la ciudadanía, la expresión de una adhesión a la modernidad, a "los nuevos tiempos" y a la "nación boliviana", pero también la construcción de un sindicalismo autónomo y contrahegemónico. Con la revolución el balompié encuentra espacios institucionales (el sindicato, la escuela, el ejército, las asociaciones de residentes y los clubes), arraigando en las comunidades indígenas y sus extensiones urbanas, sobre todo entre las nuevas generaciones. Más tarde, durante la dictadura, fue utilizado políticamente por la resistencia, sirviendo como un espacio de libertad, un resquicio a través del cual -como diría De Certeau- los movimientos indígenas pueden "cazar furtivamente" en el mundo de la política, controlado por el ejército y los grupos criollo mestizos dominantes. El fútbol, práctica cultural apropiada, se convirtió en un instrumento "táctico" para la construcción de contrahegemonía.

\section{Fútbol y sindicalismo cocalero (1985-2005)}

En el periodo democrático que comienza en 1983, la participación política indígena se realiza desde la legalizada práctica sindical, los recién creados partidos políticos de corte indígena y, en años posteriores, desde movimientos indígenas armados como el EGTK. Después de 1985, el sindicalismo campesino gana renovada influencia debido a que se produce una expansión del mismo, a la vez que se contrae el por décadas dominante movimiento obrero, minero y fabril, que fue profundamente golpeado por la crisis económica y las reformas neoliberales.

En esos años, se acelera la colonización del trópico cochabambino ("El Chapare") debido al éxodo provocado por una sequía que devastó la agricultura de las tierras altas, la crisis económica y las políticas de ajuste neoliberal. El cierre de las minas estatales, que dejó sin trabajo y vivienda a más de 30 mil familias, provocó la migración de importantes contingentes de esta población, poseedora de una fuerte tradición sindical combativa, hacia las zonas de rápido crecimiento, rurales (el Chapare) y urbanas (El Alto 
de La Paz), las cuales serían más tarde escenarios fundamentales de las luchas populares contra los gobiernos neoliberales.

Precisamente las políticas neoliberales y la "guerra contra el narcotráfico", sobre todo desde la emisión de la Ley 1008 (1988), detonarán un conflicto que enfrentará a los campesinos productores de coca con las fuerzas militares. El Chapare será escenario de una "guerra de baja intensidad" y sometido a estado de excepción, lo cual estimulará el desarrollo de un aguerrido sindicalismo campesino. En ese marco surgirán nuevos líderes, entre los que destacará Evo Morales Ayma, agricultor oriundo de Orinoca, poblado aimara situado en el departamento de Oruro, que comenzará su ascendente carrera como dirigente sindical cocalero. Desde ahí entrará en la política partidaria, llegando a ser diputado nacional y, en el año 2006, presidente constitucional de la República.

Ahora bien, la resistencia cocalera contra las políticas represivas de la "guerra contra el narcotráfico", se articularía también mediante la organización de campeonatos de fútbol que operarán como una esfera pública plebeya, donde los campesinos intercambiarán información y llevarán adelante su lucha, organizando recurrentes bloqueos de caminos y prolongadas marchas, en los cuales Morales iría poco a poco afianzando su liderazgo político. Como otros líderes, "el Evo" comenzará su carrera sindical y política ocupando el puesto de secretario de deportes, donde acumulará el prestigio y el capital político que le permitirá convertirse en el número uno del sindicalismo cocalero.

Según Morales, su afición al fútbol se remonta a su más tierna infancia, línea que sigue Martín Sivak, periodista argentino autor de Jefazo, donde relata que Evo parecía predestinado desde su nacimiento al fútbol:

La primera palabra que pronuncio Evo fue tamta, pelota en aymara. Jugó con distintos tipos de pelotas: primero, de lana; después, de trapo. Mientras sus llamas pasteaban en los cerros él las gambeteaba en zigzag. Las yaretas y las pajas bravas hacían de arco. Trébol, el perro de la familia, examinaba el progreso. (2011)

Esa imagen de Evo niño, pastor de llamas y precoz futbolista, fue canonizada en la portada de un libro de cuentos para niños dedicados a la infancia de Morales. Las aventuras de Evito (2014) incluye cinco relatos, uno de los cuales - "Evito juega al futbol"- destaca la importancia ejemplar del fútbol en la niñez del jefe de Estado. Escrito por una colaboradora cercana de Morales (ex jefa de Gabinete), Alejandra Claros, este libro ha sido distribuido gratuitamente por el Ministerio de Comunicación, que imprimió con fondos públicos una segunda edición de 3000 ejemplares, tiraje poco usual en Bolivia. En febrero del 2015, Claros publicó Las aventuras de Evito II 
y Evito y el mar, conformando una saga escrita, según la autora, para inspirar a los niños y las niñas bolivianos a seguir el ejemplo de superación del "primer presidente indígena" cuya sacrificada trayectoria rebozaría humildad y perseverancia, amén de habilidades deportivas.

La vocación futbolística de "Evito" habría surgido durante su vida escolar, cuando haría sus primeros pinitos como organizador deportivo y mostraría sus potenciales capacidades de liderazgo, dentro y fuera del terreno de juego. Según Sivak:

A los trece años, organizó algo por primera vez en su vida: el equipo de fútbol de su comunidad. Se llamó Fraternidad y él se convirtió en el capitán y delegado. Tres años después lo eligieron director técnico de todo su cantón. Con la lana de las llamas que esquilaba y con los zorros que cazaba compraba pelotas y camisetas. Mientras dirigía, oyó que el padre y algunos vecinos decían que sería buen dirigente, buen líder. Le dio vergüenza preguntar qué significan las palabras "dirigente” y "líder”. Él solo pretendía parecerse a Carlos Aragonés, un delantero que durante quince años brilló en el fútbol boliviano. (2011)

Más tarde, en la ciudad de Oruro, Morales destinaría parte de sus magros ingresos a coleccionar el suplemento deportivo del diario Hoy, cuyos posters utilizaba para decorar su habitación. También intentaría -como Jenaro Flores- desarrollar una carrera como futbolista profesional, llegando a intentarlo -sin éxito- en el San José, importante club de la ciudad minera. Luego, durante el servicio militar, su afición por el deporte se haría aún mayor: gracias a que mejoró su preparación física, participó en eventos de atletismo en Oruro, jugando también al fútbol: "Me pusieron el apodo Pacho. Éste era un jugador de la selección nacional llamado Pacho Góngora" (en Báez y de la Hoz, 2008: 276). Su carrera deportiva daría un nuevo salto en El Chapare, donde lograría una rápida y exitosa integración en la comunidad colonizadora gracias a sus habilidades futbolísticas. Según el autor de Jefazo: "Se integró a través del fútbol. El domingo del debut -todavía recuerda el sombrero y las zapatillas que usó- hizo varios goles y resultó el mejor jugador de la cancha. Los lugareños empezaron a querer jugar con él, a preguntarle por su vida, por cuánto tiempo se quedaría." (Sivak, 2011).

Cargado de entusiasmo y popularidad, Morales daría una muestra más de su capacidad de organización y liderazgo deportivo: "Fundó un equipo, Nuevo Horizonte, con el que salió campeón en el torneo de la Central 2 de Agosto." El paso siguiente fue su integración al sindicato, organización local que "cumplía funciones que el Estado no cumplía", como la construcción 
de caminos, escuelas y, desde luego, campos de fútbol, pero que también mediaba en problemas matrimoniales y rencillas familiares. De una forma casi natural, Morales fue nombrado Secretario de Deportes del sindicato San Francisco de la Central 2 de Agosto, articulando simbióticamente la actividad sindical con la actividad deportiva.

Evo incrementó su popularidad y capital social como organizador de campeonatos e intercambios deportivos, llegando a ser, gracias al vínculo entre el deporte y el activismo sindical, secretario general y secretario ejecutivo de la Federación del Trópico; finalmente, fue elegido secretario general de las seis federaciones de campesinos cocaleros del Trópico cochabambino, puesto que mantiene hasta el día de hoy. Su liderazgo sindical creció mano a mano con su afición deportiva y su radicalización política; esta última se produjo sobre todo a raíz de la Masacre de Villa Tunari en 1988, cuando las fuerzas gubernamentales asesinaron a once cocaleros en el marco de las políticas de "erradicación" de la hoja de coca.

Morales desplegó su labor deportiva y política más allá del entorno inmediato de su comunidad, estableciendo vínculos con otros actores sociales y políticos en un espectro ampliado con sectores tradicionalmente combativos, como el minero:

Responsable de organizar los torneos [de fútbol], invitaba a los mineros de Catavi [a cientos de kilómetros de El Chapare, con fuerte tradición de lucha sindical y política] con quienes después de jugar cocinaban y muchas veces terminaban bailando y tocados por la cerveza y el alcohol puro. (Sivak, 2011)

Así, entre partidos de fútbol y celebraciones festivas, pero también en marchas y huelgas de hambre, Evo forjó un liderazgo en la lucha sindical y en la actividad política. ${ }^{4}$

\section{El fútbol en el "gobierno indígena" de Evo Morales (2006)}

La impronta del fútbol en la vida de Morales no es un asunto del pasado, utilizado con el objeto de afianzar su posición de liderazgo en el mundo

\footnotetext{
${ }^{4}$ Morales, con su habitual estilo coloquial, narró a un auditorio infantil cómo venció la tentación del alcoholismo: "[...] yo jugaba, mi primer apodo en Chapare era joven pelotero, no era compañero Evo. Entonces el joven pelotero en la cancha jugaba, el deporte es integración, una vez jugamos el domingo en la tarde, mis compañeros me llevaron a la chichería, tomamos un poco de chicha, mis compañeros un poco se emborracharon, yo también un poco giradito, mis compañeros del mismo equipo queriendo pelearse / Yo como juez separando, por querer separar casi me hago pegar yo más, ese momento me enojé, '¿qué estoy aquí haciendo?', me he levantado, me he ido a mi chaco [terreno] caminando a dormir, después ya dije 6 meses ni una gota de chicha, ni cerveza, me he castigado." Moraleja: "el autocastigo sirve mucho queridos estudiantes, chicas y chicos, sirve, hay que proponerse, quiero ser algo en la vida, está en manos de ustedes [...]” (Discurso Presidencial, Cambio, 17.10.2015).
} 
sindical cocalero o, más recientemente, su liderazgo político en el MAS-IPSP. ${ }^{5}$ Esa pasión se acentuó cuando fue elegido presidente de la República (2006). Si bien el fútbol y en general el deporte, no llegó a ser un asunto de Estado, sí se convirtió en un tema privilegiado en su política social y en su actividad protocolaria. El fútbol ocupa un espacio inamovible en su agitada agenda presidencial, se mantiene informado de los grandes acontecimientos futbolísticos mundiales y nacionales, a la vez que protagoniza -con su "Equipo presidencial" - encuentros cotidianos de "fulbito", tanto en la sede presidencial, como en sus múltiples viajes dentro del país e incluso en el extranjero. ${ }^{6}$

El "contacto con el pueblo" y la "diplomacia deportiva" ha incluido la invitación al país y el encuentro con personalidades mundiales del fútbol como Maradona, Ronaldinho, Messi y el "Pibe" Valderrama, Blatter e Infantino. Entre sus "amistades deportivas" destaca Diego Armando Maradona, con quien ha establecido -apadrinado por Fidel Castro- una relación personal y ha compartido actividades deportivas y mítines políticos. Por ejemplo, en la (Contra)Cumbre de las Américas de Mar del Plata, en 2006, Morales y Maradona (vestido con una camiseta estampada con la frase "Stop Bush"), junto con otros líderes del "socialismo del siglo XxI" -como Hugo Chávez- expresaron su rechazo a la propuesta de Estados Unidos de establecer una zona continental de libre comercio (ALCA), con la famosa consigna “ ¡Alca, alca, al carajo!”.

Según Sivak, el presidente habría invitado a Maradona a jugar un partido en El Chapare para celebrar su primer año de gobierno. Aunque ese encuentro no se concretó, "el Diego de la gente" ha sido un importante aliado en la cruzada emprendida por el presidente contra el veto a los escenarios de altura, propuesto por la FIFA. El rebelde futbolista y asiduo crítico de la FIFA protagonizó un partido en la categoría senior-jugadores argentinos de renombre contra estrellas del fútbol boliviano- con Evo Morales. Finalizado el encuentro, reportado en medios internacionales con titulares como "Gol a la FIFA", Morales le otorgó a Maradona la medalla al mérito civil "Libertador

\footnotetext{
5 El MAS (Movimiento Al Socialismo) es un partido político concebido como un "Instrumento por la Soberanía de los Pueblos" (IPSP). Es el partido de gobierno desde 2006, con una aplastante mayoría en las cámaras legislativas. Morales es su líder supremo (ver García et al., 2014).

${ }^{6}$ En la entrega de obras deportivas en barrios y comunidades, Evo protagoniza partidos de fulbito, íntegramente transmitidos por la televisión pública a todo el país. Sus giras internacionales también suelen incluir partidos; por ejemplo en Bruselas, en 2015, durante la cumbre UE-CELAC (Comunidad de Estados Latinoamericanos y Caribeños), jugó contra residentes bolivianos ("Bolivia Roots"); en ciudad de Panamá, asistió a la Cumbre de las Américas y jugó con los participantes en la "alternativa" Cumbre de los Pueblos; en Italia, se midió con exjugadores del AC Milán. El 2016, Morales ha sufrido una lesión en la rodilla que lo ha alejado del terreno de juego.
} 
Simón Bolívar", mientras Marco "el Diablo" Etcheverry, uno de los jugadores más populares del país, le regaló una camiseta de la selección boliviana. Entonces, el "D10S" declaró: "Blatter no sabe lo que es jugar al fútbol. Es ridículo". "Están jugando con la alegría y la pasión de la gente". "Yo, con 47 años y con el presidente [Morales], hemos demostrado a la FIFA que se puede jugar acá [en La Paz, a 3600 m s. n. m.]”. Remató asumiendo motu proprio la representación argentina: "En nombre de todos los argentinos les digo que no le tenemos miedo a la altura" (Maradona, citado en El Clarín, 18.03.2008). ${ }^{7}$

$\mathrm{El}$ "derecho a jugar donde se vive" ha sido una causa fundamental en el nacionalismo deportivo boliviano, que ha debido hacer frente a una permanente y ya rancia reclamación por las "inhumanas condiciones" que impondría la altura a los jugadores no andinos. Por ejemplo, Uruguay desistió de participar en el campeonato sudamericano de 1963 debido a que las sedes eran La Paz y Cochabamba, ambas por encima de los 2000 m s. n. m., mientras que Argentina envió un elenco secundario por la misma razón. Entre las acciones en contra del veto a la altura, que podría afectar también a otros países como Ecuador, Colombia y México, Morales ha desplegado un intenso lobby con las autoridades de la FIFA y la CONMEBOL, para evitar -con éxito hasta ahora- que se consume dicha prohibición y demostrar que la altura no es el "único gran jugador" boliviano (Galeano, dixit).

Entre las acciones desplegadas por Morales por la "justa causa" de jugar -como diría Galeano- "sobre las nieves", destaca -además del partido con "Diego y sus amigos" - una demostración in extremis de la inocuidad de la altura: en el 2007, el presidente y su equipo practicaron un publicitado juego en una elevada montaña de los Andes, a una altura superior a los $6000 \mathrm{~m} \mathrm{s.} \mathrm{n.} \mathrm{m.}$ Este acto espectacular puede interpretarse como una protesta contra las pretensiones de la FIFA, pero también -en concordancia con la tradición sacrificial del movimiento popular boliviano- como una forma de presentar al presidente como un "superhombre andino", capaz de someterse a riesgos extremos por una causa nacional justa.

\footnotetext{
${ }^{7}$ Sobre las pasiones nacionalistas que despierta la altura como "palabra-trampa", Mendoza señala: "Cuando se menciona el veto a la altura, es la colonia la que habla" (p. 190) y califica al veto como una "gambeta a lo indígena" por parte del "Mercosur deportivo" (Argentina, Brasil, Uruguay y Paraguay) contra el "Pacto andino" (Bolivia, Ecuador y Colombia). La altura también provoca tensiones internas en Bolivia: "La aceptación de la altura como emblema identitario nacional [Bolivia es un país 'altiplánico'] oculta los bajos instintos del centralismo, que [contrapuesto a lo nacional popular] legitima mediante esa vía, con el fútbol y a pesar de él, los beneficios económicos de ser sede de eliminatorias al mundial y, sobre todo, la importancia simbólica de las capitales políticas de cada país." (Mendoza, 2000: 191).

${ }^{8}$ Expresiones tomadas de la nota "Galeano y su afición creativa por el fútbol", publicada a propósito del fallecimiento de este escritor uruguayo (La Razón, 17.4.2015).
} 
Morales, en el ejercicio de la presidencia del país, pudo cumplir uno de sus sueños de infancia: militar en un equipo de primera división. En el 2008 fue incluido en la nómina del club Litoral de La Paz, con el cual jugó un partido; su segundo fichaje fue en un club de segunda división, el Sport Boys Warnes, con sede en una provincia en el departamento de Santa Cruz, zona por entonces muy hostil al gobierno de Morales. Gracias a su popularidad como líder indígena de izquierda, así como por sus credenciales como promotor del deporte, Morales también es miembro honorario de algunos clubes extranjeros como el Belgrano de Córdoba (Argentina, que igualmente hizo socio honorario a Galeano).

Por último, dado que los medios de comunicación oficiales se esmeran por mostrarlo- es habitual ver al presidente jugando partidos de fútbol en los pueblos que visita rutinariamente para inaugurar campos deportivos, pero también protagonizando duelos deportivos en el extranjero contra diversos rivales. Asimismo, se le ha visto compartir platea en algunos grandes escenarios deportivos del mundo con otros líderes políticos, sobre todo cuando juega la selección boliviana o se disputan lugares de privilegio en el fútbol mundial de selecciones, sin descartar algunos encuentros entre afamados clubes a nivel planetario. Por supuesto, Evo es un fan de la selección boliviana, a la cual ha ofrecido su apoyo incondicional y diversos premios por su clasificación para la Copa Mundial ("lo que quieran si clasifican"), anhelo que aún no ha visto cumplido durante su gobierno, cuando se han disputado dos eliminatorias (Sudáfrica 2010 y Brasil 2014) y está en proceso una tercera (Rusia 2018). ${ }^{9}$

La extensa política deportiva del gobierno de Morales merece un estudio detallado que excede este artículo, sin embargo podemos hacer algunas referencias generales. Entre el 2006 y 2016, ${ }^{10}$ decretó que los partidos eliminatorios de la "verde" fueran transmitidos por televisión abierta estatal a todo el país; ha creado el Ministerio de Deportes, está en proceso una

\footnotetext{
9 Bolivia ha participado en tres ediciones de la Copa Mundial, dos por invitación y una por clasificación (1994, en Estados Unidos). Morales ha mantenido una relación cercana con los "héroes" del 94, invitándoles a compartir escenarios deportivos y sociales, ofreciéndoles también cargos políticos (por ejemplo, Milton Melgar fue viceministro de deportes y Tito Montaño es ministro de deportes).

${ }^{10}$ Durante la dictadura de Bánzer (1971-1978), Bolivia fue por segunda vez sede de un evento regional, después del Sudamericano de Fútbol en 1963: los VIII Juegos Bolivarianos (La Paz, 1977), para lo cual se construyó una importante infraestructura deportiva (estadio olímpico, piscinas olímpicas, velódromo, polígono de tiro, etc.). Posteriormente, se organizaron otras versiones de estos Juegos (XII edición, 1993, con sede en Santa Cruz y Cochabamba; XVI edición, 2009, en Sucre). El gobierno de Banzer organizó también un rally automovilístico anual, que recorría los polvorientos caminos que unían "toda" la geografía boliviana, presentado como una fiesta de integración nacional y advenimiento de la modernidad.
} 
nueva Ley de Deportes y ha impulsado la construcción de infraestructuras deportivas, así como la organización de eventos de ámbito local, nacional e internacional, en diversas disciplinas. Uno de esos megaeventos ha sido la incorporación del país al Rally Dakar durante tres años sucesivos (2014, 2015 y 2016; en 2017 está previsto repetir), para lo cual el gobierno ha invertido aproximadamente cinco millones de dólares en el pago de derechos a la firma organizadora, la francesa ASO. También se han organizado los Juegos Bolivarianos en su XVI edición (Sucre, 2009) y se preparan los XI Juegos Deportivos Sudamericanos (ODESUR, 2018, Cochabamba), para los que se construirá un megaescenario deportivo ("El batán”, para 60 mil espectadores y un costo estimado de 60 millones de dólares), expropiando para ello la sede del hipódromo, símbolo del estatus de la élite en retirada. ${ }^{11}$ Por último, Evo ha gestionado personalmente con la FIFA, la sede para un campeonato mundial en divisiones menores, "garantizando" que el Estado construirá tres megaescenarios deportivos. Como ese evento podría ser en categoría femenina, Morales ha manifestado su deseo de convertir a El Chapare en una "potencia mundial del fútbol femenino".

El presidente ha promovido múltiples actividades deportivas, tanto comunitarias como de alto rendimiento (numerosos campeonatos, maratones y juegos), pero también "ha entregado" más de tres mil campos deportivos a lo largo y ancho del país, así como ha "garantizado" la construcción de grandes escenarios deportivos y centros de alto rendimiento, contribuyendo igualmente a mejorar las instalaciones deportivas de algunos "grandes clubes” privados. Morales concede tal importancia a la construcción de infraestructuras y la organización de competiciones deportivas, que ha llegado a declarar, durante la inauguración del estadio "Comandante Hugo Chávez Frías” en Chimoré (24.6.2105), que su gobierno compraría cuatro aviones para 50 pasajeros, para trasladar a los equipos de fútbol estudiantiles que participarán en el campeonato interdepartamental que se realizará en dicha localidad (Bolivia TV, 25.06.2015).

Como retribución a su labor de mecenas, varios campos y eventos deportivos han sido bautizados con el nombre del presidente: "Los estadios de Chulumani, Coripata y Coroico en La Paz; Villazón en Potosí; Loreto en Beni (dato de Ademaf); de Ivirgarzama y Villa Sebastián Pagador

\footnotetext{
${ }^{11}$ El gobierno ha desarrollado obras de gran magnitud (algunos hablan de "La era Mega"), incluyendo infraestructuras deportivas, generando algunas polémicas. Por ejemplo, el estadio "Hugo Chávez" que costó 2.87 millones de dólares, con capacidad para 15 mil espectadores, está situado en Chimoré, con apenas 20 mil habitantes. Según informes oficiales, entre el 2006 y 2013, se han invertido más de 230 millones de dólares con ese fin -la mayoría en el programa presidencial "Bolivia cambia, Evo cumple" (ver Cambio, 11.9.2013).
} 
(en construcción) en el distrito 14 de Cochabamba [...] llevan su nombre. [...] se suman los coliseos de Alto Obrajes y el de Cochabamba, que ya fueron entregados. También está en funcionamiento la Villa Olímpica Evo Morales en San Joaquín, Beni. Datos del Sistema de Contrataciones Estatales (SICOES) han dado a conocer que existen tres coliseos en proceso de construcción con el nombre de Morales, uno en San Borja y dos en Chuquisaca." También los "Juegos Deportivos Estudiantiles Plurinacionales 'Presidente Evo'”, una prueba de $10 \mathrm{~km}$ en Santa Cruz. En Madrid, la Embajada de Bolivia y el Consulado General, en coordinación con la Liga Deportiva de Bolivianos, LIDEBOL, organizaron el campeonato de fútbol infantil "Evo Morales Ayma" (boletín de la Embajada de Bolivia en España, agosto 2013).

Asimismo, Morales ha buscado influir en el fútbol profesional boliviano y, particularmente, en la Federación Boliviana de Fútbol (FBF), una organización civil celosa de su autonomía respecto al gobierno que, sin embargo, se ha debilitado a raíz de los escándalos internacionales desatados en la FIFA en el 2015. La presunta participación de la dirigencia boliviana en varios de esos escándalos, ha permitido desmantelar la rancia directiva, cuyos miembros están enfrentando procesos judiciales bajo cargos de corrupción. Precisamente, uno de los objetivos de la Ley del Deporte que se está elaborando es incrementar la presencia de la regulación estatal sobre la práctica deportiva. Esto ha provocado reacciones entre las organizaciones deportivas de diversas disciplinas que ven amenazada su autonomía, pero también vislumbran una oportunidad para fortalecer sus siempre precarias finanzas.

Evo considera que el deporte es una práctica moralmente virtuosa y físicamente provechosa para el conjunto de la población, especialmente para los jóvenes, al mantenerlos disciplinados y alejados de los vicios y el ocio. Según ha declarado con frecuencia, el deporte también es fundamental para promover la integración nacional, fortalecer el sentimiento nacionalista e incrementar el prestigio nacional en el extranjero, especialmente cuando se trata del deporte de alto rendimiento. Esta afición por el deporte ha encontrado un sonoro eco entre sus colaboradores cercanos, que también se han involucrado en distintos eventos y actividades deportivas, a la vez que han contribuido discursivamente a dotar de sentido esta labor. Por ejemplo, el vicepresidente Álvaro García Linera declaró:

Un pueblo trabajador, esforzado con conocimiento científico y tecnológico, debe tener una población disciplinada en el deporte [...] Queremos llevar a jóvenes que vayan a las Olimpiadas y que nos hagan lagrimear de orgullo al cantar el Himno 
Nacional, cuando traigan una medalla de oro, de plata y de bronce, y eso es de abajo, y comenzar desde la raíz. (Cambio, 11.9.2013)12

\section{La indianidad futbolística de oposición (2004)}

Felipe Quispe Huanca (n. 1942), líder aimara conocido como "El Mallku", ${ }^{13}$ adquiere protagonismo entre los años noventa e inicios del nuevo milenio, cuando organiza unas aguerridas movilizaciones campesinas en las zonas del altiplano, contra los gobiernos "neoliberales" de turno (2000, 2001 y 2003). Formado como historiador, fundó el Ejército Guerrillero Tupac Katari (EGTK), grupo armado surgido en la segunda mitad de los ochenta, en el cual participó también el actual vicepresidente de Bolivia, Álvaro García Linera, así como su compañera de entonces, la mexicana Raquel Gutiérrez. Quispe, al igual que la pareja García-Gutiérrez, fue detenido por las fuerzas de seguridad del Estado y pasó cerca de seis años en prisión, para finalmente ser liberado sin cargos. "El Mallku", diputado nacional y candidato a la presidencia de la República en 2002 y 2005 por el Movimiento Indígena Pachacuti (M.I.P.), ha librado sus batallas políticas para reivindicar un lugar de privilegio para los "indios" desde el movimiento sindical, la lucha armada, la historiografía, la política parlamentaria y la cátedra universitaria, pero también desde el mundo del fútbol.

"El Mallku" remonta su pasión por el fútbol a la niñez. En su comunidad de origen, en un entorno de pobreza material, jugaba fútbol con una t'ejeta (pelota de trapo) que fabricaba juntando lluch'us (gorras andinas)

\footnotetext{
${ }^{12}$ La vinculación del deporte a la política no es exclusiva de Morales; otros presidentes bolivianos, como Hugo Banzer y Carlos Mesa, también hicieron pública su pasión deportiva. Tampoco se limita a Bolivia; por ejemplo, en Argentina son conocidos los casos de Juan Domingo y Eva Perón, Menem y Macri; en Ecuador y Venezuela destacan Abdalá Bucarán y Hugo Chávez, etc. En fin, más allá de Latinoamericana encontraremos numerosos ejemplos, tanto en gobiernos democráticos como autoritarios, capitalistas o comunistas (ver, por ejemplo, González, 2002; Kuper, 2012; Silva, 2015; Segurola, 1999). Existe la tentación de calificar a estos gobiernos, o al menos a sus políticas deportivas, como populistas, tentación que preferimos evitar aquí, pues nos interesa más destacar la especificidad del gobierno de Morales que señalar sus afinidades difusas con otros casos. "Populismo" es un nombre extremadamente elástico, utilizado para referirse a un cierto "estilo político" que se aplica tanto a políticos de izquierda como de derecha, así como para calificar el "contenido social" de las políticas y programas redistributivos. Por la forma o por el contenido, "populismo" es un término con una gran carga ideológica, utilizado para generar suspicacia o rechazo contra algunos políticos y gobiernos, atribuyéndoles un carácter demagógico y un fin no legítimo, mediante acciones o discursos que -a menudo ejecutados por un inescrupuloso "caudillo"-explotan el sentimentalismo "irracional" de las "masas". PPEn

${ }^{13}$ Mallku: término aimara que se refiere al "espíritu de las alturas/montañas", donde mora el cóndor, ave andina de carácter totémico. Por extensión, designa a las autoridades y liderazgos indígenas más importantes; puede traducirse de manera aproximada como "líder supremo" (ver Mamani, 2003).
} 
con sus amigos. Continuó practicando en su juventud, cuando trabajó en los centros mineros; más tarde, continuaría jugando en la ciudad de La Paz e incluso, como Flores y Morales, llegó a tentar a la suerte -sin éxito- en un club profesional. Según sus propias palabras: "Jugaba como lateral por la izquierda, incluso me fui a probar a 31 de octubre. En esa época todo era amor al deporte, nadie te pagaba nada. Fui jugador de Bolívar de Llallagua, también en Quechisla. Era muy aficionado”.

También cuenta Quispe que más tarde, como diputado de la República, dedicó parte de su tiempo y recursos a promover el fútbol en su comunidad, puntualizando que esa labor fue realizada tanto por interés personal, como porque sus propios representados le demandaban que apoyara, como diputado y dirigente comunal, la práctica del fútbol entre los niños. Estas declaraciones recuerdan las realizadas por el presidente Morales cuando se le ha preguntado por qué a su gobierno le preocupa tanto la construcción de infraestructuras deportivas en pueblos y comunidades, lo que pone de manifiesto que la pasión por el deporte no es algo simplemente impuesto "desde arriba", sino que está profundamente arraigada en la vida cotidiana de las comunidades y los barrios indígenas del país. Volviendo a las declaraciones de Quispe, éstas dejan entrever que en las comunidades la importancia del deporte es equivalente a la de la educación:

Cuando fui diputado, entre los años 2002 y 2003, ganaba alrededor de 20000 bolivianos, el dinero me sobraba, era por demás, entonces la gente del campo, de mi sector, me obligó a crear escuelas de fútbol en mi región. Obedecí y las implementamos, pero confrontamos con problemas. Tenemos cualquier cantidad de maestros interinos rurales, pero no entrenadores. Encontramos al compañero Gabino Rojas y con él preparamos el andamiaje para esos centros, pero no marchó. (Quispe, en La Razón, 7.4.2014)

Sin embargo, esa experiencia fallida como promotor del fútbol indígena comunitario le habría dado el impulso para emprender su participación en el fútbol profesional, aunque no como jugador sino como dirigente deportivo: "Entonces llegó a mi comunidad Mario Callizaya, entrenador de las divisiones inferiores de Bolívar, y surgió la idea de conformar un club con gente de nuestro sector, y así empezamos nuestro periplo en la AFLP [Asociación de Fútbol de La Paz]" (en blog ascensobolivia, abril del 2014).

Precisamente en el 2004, en una fecha altamente simbólica y disputada como el 2 de agosto, "El Mallku" creó el Club Deportivo Pachakuti en un acto realizado en un lugar también cargado de simbolismo: la Sede de 
la Confederación Sindical Única de Trabajadores Campesinos de Bolivia (CSUTCB).${ }^{14} \mathrm{El}$ nombre del club había sido elegido "porque en la lengua aimara Pacha es tiempo y espacio, y Kuti es la vuelta, o sea, nosotros estamos pensando en volver a lo que fuimos antes, más fortalecidos, transformar el deporte, que está muy monetizado, muy elitizado, muy privilegiado." El término "Pachakuti" remite a las reivindicaciones indígenas y ha sido ampliamente utilizado en las últimas décadas por las organizaciones, liderazgos e intelectuales aimaras y quechuas para señalar que ha llegado el tiempo de una transformación radical, que termine de una vez por todas con el prolongado ciclo de la dominación colonial, externa e interna, y ponga el mundo "al revés" o, mejor, en la posición correcta. ${ }^{15}$

Según Quispe, el fútbol profesional es un ámbito de la vida social boliviana en el que también se ha establecido un virtual "apartheid", bajo el control de dirigentes, entrenadores y jugadores de origen "k'ara" o "criollo/ /mestizo" que dejan fuera a las poblaciones indígenas. Así, éstas se verían privadas de participar en un espacio de gran visibilidad, que les permitiría ganar reconocimiento social como miembros de una "raza" que, según un eslogan indianista de la década de los setenta, también en el fútbol permanece "oprimida, pero no vencida". Al respecto, declara este líder:

[El fútbol profesional lo] Manejan unos cuantos dirigentes; por ejemplo, en la Asociación de Fútbol de La Paz hay una rosca bien cerrada, entonces a nosotros nos hacen pagar el derecho de piso, hasta ahora no podemos avanzar, crecer; por ello también elegimos el nombre, pues tiene que haber un cambio total, que el fútbol llegue

\footnotetext{
${ }_{14}$ Existe una prolongada disputa en torno al 2 de agosto, desde que fue instaurado como "Día del Indio" por Germán Busch en 1939. En 1953, durante la revolución, en dicha fecha se firmó el Decreto de la Reforma Agraria, por lo que pasó a celebrarse como "Día del Campesino". Por su parte, Morales (2006) declaró el 2 de agosto "Día de la Revolución Agraria y Comunitaria", para luego (2013) designarlo como "Día del Antimperialismo" (ver Nicolás y Quisbert, 2014: 239).

15 Silvia Rivera Cusicanqui, ha contrastado -retomando a S. Thompson- el término "Pachakuti" con el de "Revolución", señalando que ambos corresponden a una concepción distinta de la historia y del cambio social. Mientras "revolución" sería un concepto occidental que concibe un salto en la historia en términos de un progreso evolutivo lineal que implica una ruptura radical con la tradición, "Pachakuti" sería un concepto indígena que refiere más bien a un reinicio de la historia, concebida en términos circulares, como un retorno a las raíces. Por lo tanto, calificar como "revolución" a las grandes movilizaciones indígenas implicaría un "silenciamiento de las peculiaridades de la lucha indígena" (2011). El gobierno de Morales ha utilizado tres términos para caracterizar las transformaciones que está llevando adelante: Pachakuti, Revolución y "Proceso de cambio"; la primera ha sido paulatinamente abandonada, la segunda se usa sobre todo para destacar las afinidades con otros procesos latinoamericanos (en particular con la Revolución cubana), mientras el tercero -más inocuo- es dominante en el discurso oficial.
} 
también al pueblo, porque en este momentos simplemente es de algunas personas privilegiadas. (Quispe, en La Razón, 7.4.2014) ${ }^{16}$

A este proyecto, destinado a "promover y fomentar la práctica del futbol indio indígena [sic] en el campo, así como de otras disciplinas y eventos culturales deportivos intercomunales, provinciales, departamentales, nacionales e internacionales" (perfil de Facebook del Club), Quispe ha dedicado gran parte de su tiempo y sus desvelos en los últimos años, sobre todo desde que se retiró de la política activa y rompió con Morales y García Linera, a quienes ha acusado reiteradamente de traicionar la causa indígena (Quispe, 2013). Esa dedicación, que ha incluido la creación de "Escuelas de fútbol" comunitarias, busca incursionar en el fútbol profesional para demostrar que los indígenas, especialmente la "raza" aimara, pese a las usualmente paupérrimas y desinteresadas condiciones en las que practican este deporte, pueden llegar a ser protagonistas y campeones en el fútbol de alto rendimiento. Según Quispe, la "indianización” del fútbol boliviano profesional es la única manera de superar el carácter colonial y racista de las instituciones deportivas departamentales y nacionales $\mathrm{y}$, por lo tanto, terminar con las recurrentes malas actuaciones de los equipos profesionales y de la selección boliviana en las competiciones internacionales.

"El Mallku" anhela que el Club Deportivo Pachakuti, como "un equipo del campo y de esencia y presencia aymara" ascienda a la "Primera A" y, una vez ahí, pueda "romper ese estigma racista que prima en los "Equipos Profesionales" que no admiten a los indios de apellido originarios, más [sic] prefieren extranjeros que nacionales, por eso a nivel internacional se hacen golear una vergüenza estos equipos." (perfil de Facebook, 6.6.2015). Quispe reivindica el protagonismo indígena en el ámbito del fútbol profesional boliviano, apelando al apellido como un marcador de pertenencia étnica, algo muy común en Bolivia: "Queremos escuchar que se nombren

\footnotetext{
${ }_{16}$ Pablo Mamani ha llamado la atención sobre el racismo en el fútbol boliviano, en términos similares a los de Quispe: "En nuestro medio la pregunta es: ¿por qué los aimaras o quechuas no juegan en la misma dimensión poblacional en el fútbol profesional? ¿Los aimaras o quechuas acaso no juegan el fútbol entre los 500 y 4000 metros sobre el nivel del mar? ¿No se observa que en los campeonatos locales se juega al fútbol con igual pasión que en Brasil? ¿No sirve la historia de que algunos líderes aimaras como Jenaro Flores hayan hecho su carrera jugando al fútbol o incluso el actual Presidente de Bolivia? ¿No se observa niños con cualidades importantes en campeonatos zonales y en las provincias? Esto es observable en Achacachi, Patacamaya, Viacha, Chulumani, Palos Blancos, Chapare; en Karangas, El Alto, etc. Pues, la afirmación "de que no existe racismo en el fútbol boliviano" es simplemente ocultar este colonialismo que aquí definimos como "racismo estructural" dado que no habría materia para polemizar del racismo en el fútbol contra aimaras o quechuas." (ver "Futbolistas aymaras y el racismo en Bolivia", La Razón, 2.10.16).
} 
apellidos originarios como Mamani, Quispe, Condori, Tarqui, apellidos nuestros, porque hay mucha discriminación, entonces estamos apuntando a llegar a nivel profesional con nuestro propio elemento, para demostrar el orgullo indio que tenemos." (en blog ascensobolivia). ${ }^{17}$

Por último, para este líder aimara, incursionar en el fútbol profesional con un equipo netamente indígena implica la puesta en marcha de un programa más amplio de "indianización" del país, en el cual ese deporte serviría como escenario público y espectacular donde llevar adelante y de manera dramática un combate por el prestigio y el poder de la "raza indígena". Su proyecto indianista y descolonizador no le asigna al fútbol -como en la política de Morales- la tarea de llevar adelante la integración nacional o de incrementar el prestigio nacional en el exterior, más allá de las rivalidades étnicas o regionales, sino más bien la de servir como campo de batalla entre "las dos Bolivias", la indígena y la criolla-mestiza-chola.

\section{Comentarios finales}

El "fútbol indígena" es un fenómeno que desborda las fronteras bolivianas y se manifiesta en el ámbito latinoamericano, como lo evidencia la organización de la primera Copa Americana de Fútbol de los Pueblos Indígenas (en julio del 2015, con sede en Chile), en la cual participaron ocho equipos (Argentina, Bolivia, Chile, Colombia, Ecuador, México, Paraguay y Perú) y se coronó campeón el equipo representante de Paraguay, seguido por Colombia, Chile y Bolivia. ${ }^{18}$ Para conocer el alcance de esa articulación, así como su vínculo con los procesos de colonialidad/descolonización, es necesario continuar investigando sobre el "fútbol indígena", tanto en el ámbito local y nacional, como internacional, sobre todo en el marco del creciente protagonismo político de los pueblos indígenas.

\footnotetext{
${ }^{17}$ Si bien el gobierno de Morales ha insistido en la "indianización" del Estado y la sociedad bolivianos, no ha reivindicado la "indianización" de la selección nacional de fútbol o de los equipos profesionales, "grandes" o "pequeños". Evo, que es hincha del club Bolívar (el Mallku es aficionado al The Strongest, archirrival de Bolívar), se ha interesado más por el rendimiento -sobre todo internacional- de la "verde" y de esos clubes, apoyándoles con recursos públicos; en el caso de los clubes, por ejemplo, ha colaborado en la mejora de infraestructuras, llegando incluso a declarar asueto laboral para que el público asista y los apoye en sus encuentros internacionales.

${ }^{18}$ Este evento surgió a partir del "Encuentro Sociocultural y Deportivo de Pueblos Originarios", organizado por la Fundación Gol Iluminado, la Asociación Nacional de Pueblos Originarios, ANPO y la Corporación Nacional de Desarrollo Indígena, CONADI, que fue designado "Evento Deportivo del Año por la Paz y el Deporte” (2013) por la Fundación Peace and Sport, del Alto Patronato del Príncipe Alberto II de Mónaco. En Colombia, la Organización de los Pueblos Indígenas de la Amazonía Colombiana, OPIAC, convocó en el 2014 el Primer Campeonato de fútbol indígena en la región amazónica, con la divisa "Más allá del balón". En Bolivia, la CSUTCB ha organizado varios campeonatos nacionales entre pueblos indígenas, representados por federaciones sindicales departamentales.
} 
Este ensayo aporta una investigación sobre Bolivia, prestando atención a los procesos de difusión y apropiación de esta práctica y afición deportiva en los liderazgos, movimientos y gobiernos indígenas del país. Existen indicios suficientes que muestran que el fútbol se difundió tempranamente en las comunidades indígenas del altiplano boliviano, donde se popularizó como una práctica cultural "ajena" aunque no necesariamente impuesta, ya que mantuvo un carácter dual desde una perspectiva colonizadora/ /descolonizadora. Es decir, el fútbol no se impuso de manera forzada, pues no formó parte de un programa de colonización, como había ocurrido con la religión católica o con algunas prácticas deportivas en otros escenarios coloniales (ver, por ejemplo, Appadurai, 2001).

Esa difusión habría sido relativamente espontánea, en un contexto de tensa pero real incorporación activa de las poblaciones indígenas a la sociedad boliviana. Pronto el fútbol sería apropiado en las comunidades indígenas como un instrumento para fomentar el afianzamiento de las relaciones intercomunales en un marco de confraternidad y competencia deportiva. Después de la guerra del Chaco y, sobre todo, con la Revolución de 1952, el fútbol encontró soporte institucional en las instituciones educativas y las organizaciones sindicales; particularmente estas últimas, brindaron al fútbol un marco organizado y lo convirtieron en arena para fomentar las competiciones intercomunales y, notablemente, para vehicular la disputa generacional por el liderazgo, tanto local como regional.

Precisamente, muchos de los nuevos liderazgos sindicales, exclusivamente masculinos, se forjaron en el terreno de juego y en el ejercicio de labores organizativas de carácter deportivo, las cuales habrían sido vividas como un "símbolo de los nuevos tiempos" y experimentadas como una forma de adhesión al Estado y la nación. En esta fase, el fútbol ya no sólo era favorable para el fortalecimiento de las identidades comunitarias en competición, sino también - por su articulación con el sindicalismo- un espacio de competencia por el prestigio y el liderazgo dentro y entre las comunidades, y simultáneamente -debido a la articulación entre el sindicalismo y el proyecto revolucionario- un escenario para mostrar la adhesión a la nación y para construir ciudadanía, acorde con el proyecto nacional en curso.

En una tercera etapa, el fútbol se convirtió en una plataforma de lucha sindical contra los gobiernos dictatoriales, así como de cuestionamiento del proyecto de nación propuesto por la Revolución del 52. Fue utilizado para organizar un movimiento indígena de resistencia contra la dictadura que, una vez roto el pacto militar-campesino después de las masacres de Tolata y Epizana a mediados de los setenta, había intensificado la represión sobre el campesinado. El fútbol, relativamente libre de la férrea vigilancia 
policial, serviría como esfera pública plebeya donde las nuevas generaciones indígenas, a su modo hijas de la revolución y el sindicalismo, podían discutir sobre los problemas de las comunidades y su relación con el gobierno y la sociedad nacional. Por lo tanto, el balompié fue políticamente apropiado por el movimiento indígena opositor, convirtiéndose en un valioso recurso para la formación de un amplio movimiento sindical independiente. Jenaro Flores fue el líder emblemático en este periodo.

Esa función política del fútbol, atenuada cuando se restableció el sistema democrático, renace después de 1985, en el marco de las luchas del nuevo campesinado cocalero contra las políticas represivas de los gobiernos neoliberales. Nuevamente las organizaciones sindicales y las actividades deportivas en su seno, contribuirían para organizar la resistencia a la "guerra al narcotráfico” y para formar nuevos líderes, entre los cuales destaca Evo Morales. Este oriundo aimara, influido por el arraigo que este deporte alcanzó en las comunidades del altiplano, habría desarrollado desde niño una intensa pasión por el fútbol, convirtiéndose en un asiduo jugador y aficionado, pero también en un organizador de equipos y campeonatos de fútbol, habilidades que le servirían para construir su liderazgo en el deporte comunitario y, más tarde, para hacerse un lugar en el mundo cocalero en El Chapare.

Morales no sólo llegará a ser el máximo dirigente del sindicalismo cocalero, sino también diputado y presidente de la República. Como "primer presidente indígena” de la (pluri)nación boliviana, Evo ha alimentado su carisma de líder popular desenvolviéndose como jugador de fútbol, pero también como promotor y mecenas del deporte nacional. Actuando como "secretario ad hoc de deportes" de la nación, ha implementado una política orientada a desarrollar tanto el deporte de base como el de alto rendimiento en el ámbito local, nacional e internacional. Con su gobierno, el fútbol indígena ha trascendido su carácter comunitario y sindical, para transformarse en un proyecto educativo a gran escala, así como en un espacio para la integración nacional y la búsqueda de prestigio internacional para el Estado Plurinacional.

Por último, Felipe Quispe, también dirigente sindical y figura política, ha propuesto un nuevo programa para el "fútbol indígena" boliviano, que difiere claramente del desarrollado por el presidente. "El Mallku" -desencantado con la política y crítico del gobierno de Morales-, no aspira a convertir al fútbol en una herramienta integradora y disciplinaria para todos los jóvenes bolivianos, tampoco a utilizarlo como una fuente de prestigio para el conjunto de la nación. Más bien plantea un programa de descolonización social y deportiva indianista, cuyo objetivo es promover la 
indianización/aimarización del fútbol, más allá del ámbito local o sindical. Esa incursión indígena en el "coto cerrado" del fútbol profesional, permitiría recuperar el "orgullo indio" y superar el colonialismo y el racismo que está en el origen de los sucesivos estados de frustración provocados por los fracasos de los equipos "grandes" y las selecciones nacionales.

En suma, el "fútbol indígena" boliviano se ha ido transformando a través del tiempo, pasando de ser una práctica ajena apropiada en un ámbito local, a una plataforma de vinculación indígena a la nación, pero también un escenario para una oposición al Estado "colonial" e, incluso, para una política de transformación del Estado y la sociedad boliviana. Particularmente con la llegada de Morales al gobierno, el fútbol se ha convertido en un ámbito que, desde arriba y el centro (el gobierno central), busca afianzar un sentimiento de nacionalidad con un fuerte contenido indígena. Pero también, con Quispe, se ha convertido en un espacio para la expresión de la disidencia indígena con el "proceso de cambio" y su programa de "integración nacional”, para demandar una radicalización con el objeto de profundizar el denominado proceso de descolonización y de indianización de la nación.

Es necesario investigar más sobre este tema. Se requiere profundizar en la historia del fútbol, en su relación con otros pueblos y proyectos políticos indígenas bolivianos, sobre todo en la región de los valles -predominantemente quechuas- y entre los "pueblos originarios" de las tierras bajas -el Chaco y la Amazonia, predominantemente guaraníes. Asimismo, es necesario estudiar las prácticas y las políticas deportivas entre los indígenas en los ámbitos sindicales y las organizaciones empresariales, escolares y militares, sin descuidar el papel de las instituciones estatales de ámbito local, departamental y nacional. Esta indagación debe prestar atención a la práctica deportiva, a su institucionalización y a los discursos que le dan sentido y contribuyen a los procesos de construcción subjetivos e identitarios, tanto en la vida cotidiana como en los medios de comunicación. La exploración "desGOLonizadora" tan sólo acaba de empezar.

Revisado por José Morales

\section{Bibliografía}

Albó, Xavier (comp.) (1988), Raíces de América. El mundo aymara. Madrid: Alianza.

Albó, Xavier; Barnadas, Josep (1990), La cara india y campesina de nuestra bistoria. La Paz: UNITAS/CIPCA.

Albó, Xavier; Greaves, Tomás; Sandoval, Godofredo (1983), Chukiyawu: la cara aymara de La Paz, III, Cabalgando entre dos mundos. La Paz: CIPCA. 
Albó, Xavier, Sandoval, Godofredo; Greaves, Tomás (1987), Chukiyawu: la cara aymara de La Paz, IV, Nuevos lazos con el campo. La Paz: CIPCA.

Appadurai, Arjun (2001), La modernidad desbordada. Dimensiones culturales de la globalización. Montevideo: F.C.E.

Báez, Luis; Hoz, Pedro de la (2008), Evo: espuma de plata. La Habana: Ediciones Plaza.

Bonfil Batalla, Guillermo (1987), "Lo propio y lo ajeno: una aproximación al problema del control cultural”, La cultura popular. México: Premia.

Calderón, Fernando; Dandler, Jorge (comps.) (1986), Bolivia: la fuerza bistórica del campesinado. Cochabamba: UNRISD-CERES.

Cusicanqui, Silvia Rivera (2011), "De Tupac Katari a Evo Morales. Política indígena en los Andes”, in Esteban Ticona Alejo (comp.), Bolivia en el inicio del Pachakuti. La larga luch a anticolonial de los pueblos aymara y quechua. Madrid: Ediciones Akal.

De Certeau, Michel (1996), La invención de lo cotidiano: 1. Artes de hacer. México: Departamento de Historia de la Universidad Iberoamericana y Instituto Tecnológico y de Estudios Superiores de Occidente. Traducción de Alejandro Pescador.

García Yapur, Fernando Luis; García Orellana, Luis Alberto; Soliz Romero, Marizol (2014), "MAS legalmente, IPSP legítimamente". Ciudadanía y devenir Estado de los campesinos indígenas en Bolivia. La Paz: PIEB.

González Aja, Teresa (comp.) (2002), Sport y autoritarismos: la utilización del deporte por el comunismo y el fascismo. Madrid: Alianza.

Kuper, Simon (2012), Fútbol contra el enemigo. Barcelona: Editorial Contra. Traducción de David González Raga y Fernando Mora.

Mamani, Pablo (2003), "Simbología y poder indígena después de los Kataris-Amarus y Willkas: los Mallkus en los nuevos levantamientos indígenas en Bolivia”, Centro de Documentación Mapuche. Consultado a 1.9.2015, en http://www.mapuche.info/ mapuint/mamani030600.html.

Mendoza Leigue, Adolfo (2000), "La altura en el banquillo de los colonizados", in Pablo Alabarces (comp.), Peligro de gol. Estudios sobre deporte y sociedad en América Latina. Buenos Aires: CLACSO.

Müller, Juliane (2014), "El duelo Warisata contra Achacachi: escuelas rurales, educación física y la indigenización del fútbol en el departamento de La Paz (1910-1940)", in Juliane Müller y Mario Murillo (comps.), Otro fútbol. Ritualidad, organización institucional y competencia en un siglo de fútbol popular en Bolivia (1896-2014). La Paz: Plural Editores.

Müller, Juliane; Mario Murillo (comps.) (2014), Otro fútbol. Ritualidad, organización institucional y competencia en un siglo de fútbol popular en Bolivia (1896-2014). La Paz: Plural Editores.

Nicolás, Vincent; Quisbert, Pablo (2014), Pachakuti: el retorno de la nación. La Paz: PIEB. Peñaloza Bretel, Marco Antonio (1998), Historia contemporánea del fútbol boliviano (1960-1993). La Paz: HISBOL. 
Quintana Taborga, Juan Ramón (1998), Soldados y ciudadanos. Un estudio crítico sobre el servicio militar obligatorio en Bolivia. La Paz: PIEB.

Quisbert Condori, Pablo (2014), “Tiempos de revolución, tiempos de fútbol: nacionalismo, identidad obrera y fútbol en la revolución nacional de 1952”, in Juliane Müller y Mario Murillo (comps.), Otro fútbol. Ritualidad, organización institucional y competencia en un siglo de fútbol popular en Bolivia (1896-2014). La Paz: Plural Editores.

Quispe Huanca, Felipe (2013), La caída de Goni. Diario de la "Huelga de Hambre". Qullasuyu: Ediciones Pachakuti.

Santos, Boaventura de Sousa; Meneses, Maria Paula (comps.) (2014), Epistemologías del Sur (perspectivas). España: Ediciones Akal.

Segurola, Santiago (comp.) (1999), Fútbol y pasiones políticas. Barcelona: Debate.

Silva, Luis Felipe (2015), El fútbol y la guerra: entre balas y balones. México: Planeta.

Sivak, Martín (2011), Jefazo: retrato intimo de Evo Morales. Madrid: Debate [versión electrónica, formato Kindle].

Ströbele-Gregor, Juliana (1989), Indios de piel blanca. Evangelistas fundamentalistas en Chuquiyawu. La Paz: Hisbol.

Ticona Alejo, Esteban (2000), Organización y liderazgo indígena, 1979-1996. La Paz: Universidad de la Cordillera.

Recibido: 21.12.2015

Aceptación comunicada: 13.10.2016

\section{Sergio Villena Fiengo}

Facultad de Ciencias Sociales, Escuela de Sociología, Universidad de Costa Rica

Ciudad de la Investigación, San José, San Pedro, Costa Rica

Contacto: sergio.villena@ucr.ac.cr

\section{DES-gol-ONIZACIÓN? Football and Politics in Indigenous Movements in Bolivia}

This article examines Bolivian "indigenous football”, presenting evidence and hypotheses concerning its role within sport and the processes of coloniality and decolonisation. Based on the "cultural control" theory and using secondary sources, it investigates how, during the course of

\section{DÉ-goal-ONISATION? \\ Football et politique dans les mouvements indigènes en Bolivie}

Cet essai présente une approche du "football indigène" bolivien, en suggérant des pistes et des hypothèses à propos de la place qu'occupe le sport dans les processus de colonialité et de décolonisation. Partant de la théorie du "contrôle culturel" et utilisant des sources secondaires, nous 
approximately one century, football has become established as an "appropriated culture" in Aymara and Cocalero communities and indigenous movements in Bolivia. It also demonstrates how, as part of this process, "indigenous football" has served many purposes: reinforcement of local identities, expression of a sense of belonging to a nation, trade union organization, training for leaders and indigenous networks, resistance to the onslaughts of dictatorships, opposition to neoliberal policies, promotion of policies for national integration, and essential support for the Indian opposition campaign.

Keywords: Bolivia; football; indigenous movements; political opposition; sports policy; trade unionism. nous penchons sur la façon dont, au long d'environ un siècle, le football s'est ancré, enraciné, comme une "culture propre" parmi les communautés et les mouvements indigènes Aymara et Cocalero en Bolivie. Nous mettrons en lumière la façon dont, au fil du temps, le "football indigène" a servi de multiples objectifs: renforcer les identités locales, exprimer l'appartenance à la nation, organiser des syndicats, former des leaders et des réseaux indigènes, résister au choc des dictatures, s'opposer aux politiques néolibérales, promouvoir des politiques d'intégration nationale et ouvrir la voie à un projet indianiste d'opposition. Mots-clés: Bolivie; football; mouvements indigènes; opposition politique; politique sportive; syndicalisme. 
